\title{
COVID-19 in Afghanistan: Evaluating Health Vulnerability and Identifying Controlling Mechanism
}

\author{
Najibullah Omerkhil ${ }^{1 *} \odot$, Gul Agha Sadiq ${ }^{1} \oplus$, Nisar Ahmad Kohistani $^{1} \odot$, \\ Abdur Rahim Abidi ${ }^{\circledR}$, Gul Mina Azizi ${ }^{1}$
}

Kunduz University, Kunduz, Afghanistan

2 Director, Securities Board of Nepal (SEBON), Lalitpur, Nepal

* Corresponding Author (n.omerkhilagr@gmail.com)

Received: 21 October, 2021

Revised: 07 November, 2021

Accepted: 22 November, 2021

Published: 25 December, 2021

How to cite this paper:

Omerkhil, N., Sadiq, G.A., Kohistani, N.A., Abidi, A.R., \& Azizi, G. M. (2021). COVID-19 in Afghanistan: Evaluating health vulnerability and identifying controlling mechanism. Quest Journal of Management and Social Sciences, 3(2), pp. 175-192.

Copyright (C) 2021 by authors and Quest Journal of Management and Social Sciences.

This work is licensed under a Creative Commons Attribution-Non Commercial-No Derivatives 4.0 International License.

https://creativecommons.org/ licenses/by-nc-nd/4.0/

\begin{abstract}
Background: The insistent range of coronavirus (COVID-19) crisis and its permeation into least developed countries has escalated the bar of countries fragility and susceptibility. Afghanistan is amongst the most affected countries by the COVID-19 pandemic certainly due to its poor health infrastructure and conflict-affected demography.
\end{abstract}

Objective: This study intends to assess the health vulnerability profile and identify the controlling mechanism of the North and Northeast regions of Afghanistan using the IPCC framework.

Method: A pre-evaluated online questionnaire (Google form) and mobile survey of 361 households distributed in eight provinces across both the zones to collect the primary data. Exposure, sensitivity and adaptive capacity covered the three main components of the vulnerability index, weighing method of Iyenger and Sudershan is used to estimate the fabricate vulnerability index.

Result: The province's health vulnerability status was classified into different groups based on beta distribution. Based on the vulnerability index, 62.5\% of provinces were highly vulnerable, $25 \%$ moderately and $37.5 \%$ were least vulnerable.

Conclusion: In the Northeast region people were highly vulnerable to COVID-19 in terms of sensitivity and exposure, with the low coping capacity to cope with the COVID-19 pandemic risks compare to the North zone.

Recommendation: Enhancing health and hygiene facilities and a handful of low-cost methods such as strengthening informal safety nets and introducing small-scale regional infrastructure projects, could be the most cost-effective and viable options.

Paper Types: Research Paper

Key Words: Controlling Mechanism, COVID-19 Risks, Provinces Exposures, Health Vulnerability and Adjustment Ability.

JEL Classification: I12, I14, I18 


\section{Introduction}

Coronaviruses (CoVs) are the huge accession of viruses belonging to the order of Nidovirales and the family of Coronaviridae (Husseini \& Kamal, 2020). Coronaviridae family is further classified into the four categories: the $\alpha$-coronavirus, $\beta$-coronavirus, $\gamma$ - coronavirus, and $\delta$-coronavirus (Bozkurt, Yousef \& Abdeljawad, 2020; Husseini \& Kamal,2020). The Nidovirales order is positive-sense RNA, enveloped and non-segmented viruses where the Coronaviridae family has the highest significant recognized RNA genomes, covering approximately 30 kilobases $(\mathrm{kb})$ genomes. The disease initially emerged in Wuhan, China and gradually proliferated into many countries (WHO, 2020a; Miller, 2017). The emergence of the novel coronavirus was confirmed pandemic by the World Health Organization. The disease caused by this coronavirus has been given the name COVID-19 (WHO, 2020a). The COVID-19 pandemic medical evidence shows it causes several acute respiratory infectious diseases whose main clinical symptoms include fever, dry cough, fatigue, and vocalizing in both transforming and ending lives (WHO, 2020a; Jaiswal \& Kooko, 2021; James et al., 2020). While globally 80 percent of the COVID-19 cases are reflected to be slight, the elderly, people with compromised immune systems and people with a pre-existing health disorder such as heart diseases or diabetes are deliberated to be at the higher risk ( WHO, 2020a; Miller, 2017).

The novel coronavirus impact is wide, its impact on health has been more direct and the patients and death tolls of COVID-19 are felt most acutely by communities experiencing multi-dimension and intersecting vulnerability, but socioeconomic including environmental and cultural domains impact have been direct and indirect (Bhattacharya \& Banerjee, 2021). The current COVID-19 outbreak has altered the large section of thousands of communities around the globe, particularly least developed countries including Afghanistan, which its vast section of the population has been affected by the COVID-19 pandemic regardless of their socioeconomic and health status. Afghanistan is a South Asian country with a total population of 35.53 million people, $75 \%$ of whom live in rural areas (WHO, 2020; Shah et al., 2020). Over the last 17 years, steadily the health system of the country has been succeeding with raising the coverage of healthcare services throughout the country. In 2018, a total of 3,135 health facilities were functional to ensure access of approximately $87 \%$ of the population within two hours' distance (WHO, 2020; World Bank, 2020), with only 9.4 skilled health physicians and 1.9 professionals per 10,000 individuals in the country; these physicians are disproportionately distributed across the 34 provinces of Afghanistan, with as few as 0.6 physicians per 10,000 people in rural areas and 7.2 physicians per 10,000 individuals in urban areas (WHO, 2020). The last four decades of Afghanistan armed conflict have demolished the country's infrastructure, resulting in underdevelopment and harsh economic situation, as well as widespread poverty. Millions of Afghans have left the country (Omerkhil et al., 2020) and ultimately its weak health system and limited adaptive capacity to cope with these outbreaks leading it to major disease outbreaks to the susceptible status in which the country finds itself (Omerkhil et al., 2020; Safi \& Ibrahimi, 2020), with various obstacles with healthcare delivery and controlling its double burden of diseases given the limited health literacy, shortages of skilled health workers, preventative measures, and fragile health infrastructure (Safi \& Ibrahimi, 2020). Demographic features such as a low literacy rate $(31.74 \%)$ have affected public health awareness of the community, hygiene practices and sanitation, underdevelopment and a poor economy, the deterioration of natural resources and high natural disaster exposure as well as a low adaptive capacity have made Afghanistan significantly vulnerable to natural disasters (Omerkhil et al., 2020; Saeed, 2020).

More than 218 countries and territories around the world have been affected by the current COVID-19 pandemic, Afghanistan is the 103th country on the list with 157,734 COVID-19 confirmed cases, 7,332 deaths and over 145,507 recovered cases according to Worldometer COVID-19 Data, (1 October. 2021), with no confirmed treatment but advised preventive approaches like frequent hand washing, use of masks, observance hygiene and social distancing, and Afghanistan acted early to prevent the widespread of COVID-19 ordering a 30-days countrywide lockdown and quarantine on March 24, 
2020 (Kumar, et al., 2020) while, on 22 February 2020 the first case of COVID-19 was reported from Herat city of Afghanistan when 150,000 Afghan citizens returned from the Islamic Republic of Iran to Herat province (COVID-19 update: Ministry of Public Health, Afghanistan). Therefore, mass population movement and gatherings had significantly increased the rate of active cases in the nation (Safi \& Ibrahimi, 2020).

Afghanistan is amongst the sub-set of fragile countries, due to its limited coping capacity and weak healthcare system to tackle any disaster. Because of the relevance of the COVID-19 pandemic on the health and socioeconomic livelihood of the country, there is an urgent requirement to prioritize research to evaluate the health vulnerability situation of various provinces of Afghanistan, which located in both North and Northeast regions regarding their coping and adaptation measures during pandemic struck the country. This can be achieved by evaluating health vulnerability status and identifying the controlling mechanism to the COVID-19 pandemic in the North and Northeast provinces of Afghanistan. In this study, we constructed dimensions of health vulnerability and adaptation measures for eight provinces of Afghanistan using various factors in different domains, which may propose ideas to effectuate policies and the way forward. Moreover, the study attempts to understand the impacts of war and conflicts on the local population, merging the COVID-19 outbreak which is often not at the forefront of people's thoughts. Therefore, the present research will contribute to filling the information gap by assessing the health vulnerability status of people in both North and Northeast regions using primary data, and the developed framework of this study is easily transformable to other countries in the world and can be extended to province level for policymakers on short or long-term to boost the overall health of individuals living in each province.

The present article is organized into six sections. Section I provides an introduction to the study. Section II examines the relevant literature on vulnerability for COVID-19. Section III focuses on the profile of the study and the general methodology used for the analysis of the indices. Section IV discusses all the results of the study with some discussion. Section V draws an overall conclusion of the study.

\section{Review of Literature}

The current COVID-19 pandemic has caused a vast-ranging of vulnerability on various systems across the world. The impact of COVID-19 on health and human socioeconomic systems is high and depends on the scale of the outbreak, communities development, and sensitivity besides the varieties and implementation of adaptation and mitigation measures (Omerkhil et al., 2020; Zhag et al., 2017). Vulnerability is a function of two characteristics of the system i.e. sensitivity and adaptive capacity and the character, magnitude and rate of exposure agent (Omerkhil et al., 2020), and it is the degree of susceptibility of a system and inability to cope with the adverse effects of the COVID-19 pandemic (Zhang et al., 2017). Health vulnerability has been perceived in various ways based on its context: for instance, Simplice et al., (2020) measure the 150 countries leveraged on their economic resilience to fight health vulnerability versus economic resilience to the COVID-19 pandemic mostly focused on the global sample of 150 countries across the four main regions; Asia- Pacific, Middle East, Europe and Africa, while Singh, (2020) evaluated the data on health and social vulnerability of rural India to understand the gap between social and health vulnerability to the COVID-19 pandemic and highlighted that households in rural India are highly exposed to the current COVID-19 pandemic and also equally sensitive to poor sanitation and insufficient availability and accessibility of clean drinking water and health care system. Jaiswal and Kooko (2021) studied the evaluation of occupational health risks and healthcare workers in the context of COVID-19 and highlighted for the protection of healthcare workers from the COVID-19 pandemic, there is huge requirement for quick development of sustainable approaches and measures to ensure their safety. James et al. (2020) designed a research on the assessment of health vulnerability of gender and sexual minority during the COVID-19 pandemic and health crisis, their result showed children, women and minority communities significantly faced with 
structural i.e. accessibility to housing, employment, and healthcare facilities prior to the COVID-19 pandemic situations and these producing new ones and magnifying inequities exposure and worsening healthcare facilities.

Cabril et al., (2021) investigated to identify the vulnerability of children in the access to primary healthcare in Brazil and Portugal during the COVID-19 pandemic. Their findings show both countries are more focused to promote the health of breastfeeding children, through adopting remote care strategies, i.e. teleconsultation, tele-monitoring and mobile applications but consultations were suspended for low-risk infants of these countries. Brazil interrupted the vaccination process in the first 15 days of the COVID-19 outbreak, while Portugal maintained the routine vaccination. Wyper et al., (2020) studied the population vulnerability of the countries across Europe by evaluating YLD and age structure for health status linked to serious sickness from the COVID-19, their assessment indicates countries with a high percentage of elderly residents were highly vulnerable than countries with young residents. Acharya and Porwal (2020) explored India's vulnerability in different districts based on socio-economic and ecological situations and constructed the COVID-19 health vulnerability indices to help policy-makers to focus on the districts that are more susceptible and vulnerable to the diseases. Mishra et al. (2020) evaluate and identify the indices at the sub-city level which may threaten the lockdown and social distance in four major cities of India, i.e. Delhi, Chennai, Kolkata and Mumbai through a vulnerability index and categorized the sub-city as very high, high, moderate and low in terms of vulnerability. Mukherjee et al., (2020) deliberate a four-dimensional method to vulnerability due to the rise in the current COVID-19 pandemic, where the dimensions were poverty, disruption in students' approach to mid-day meals and education, disruption of possible access to healthcare for chronic ailments and diseases caused by domestic violence and alcoholism, and Bhattacharya and Banerjee (2021) constructed indices for investigation of India's 22 major states for economic and health vulnerability and indicated that states like Madhya Pradesh, Bihar, Assam, Uttar Pradesh and Jharkhand are at the highest according to all indices in both post and pre-COVID-19, but some states i.e. Odisha, Maharashtra, Haryana and West Bengal are the only which have the high post-COVID-19 outbreak vulnerability index.

\section{Research Methods}

\section{Profile of the study area}

The Islamic Republic of Afghanistan has 652,860 square kilometer2 (WFP, 2019) including plains, hills, mountains and deserts. The republic is comprised of 34 administrative provinces and divided into 398 provincial districts, which are further split up into villages and small cities (MANAGE, 2015). The total population of the country is 35.53 million with a rural population of $74.75 \%$ with a density of 54.4 persons per square kilometer (WFP, 2019). Moreover, the high vulnerability of the population or the poor population falling into poverty is approximately $62 \%$ (MANAGE, 2015). About $30 \%$ of the total country populace have food insecurity to some degree (NRVA, 2018; Omerkhil et al., 2020; Viola et al., 2007), which, as per the Afghanistan Living Conditions Survey in 2017, has increased to more than $44 \%$ since 2014, (WFP, 2019; Omerkhil et al., 2020). Based on the Human Development Report of 2017, Afghanistan has one of the lowest human development rankings i.e., 169th out of 187 countries in the world, (ANDS, 2018).

The study was conducted in the eight provinces belonging to the North (Faryab, Jawzjan, Balkh, and Samangan) and Northeast (Badakhshan, Takhar, Kunduz, and Baghlan) of Afghanistan, which covers about $450838 \mathrm{~km} 2$ of the total land area of Afghanistan territory (FAO, 2017). These provinces are located in the North and Northeastern regions of the country at E 36 $15^{\prime} 13.8^{\prime \prime}$ and N $37^{\circ} 28^{\prime} 22.4^{\prime \prime}$ with a mean elevation of $565 \mathrm{~m}$ (1853 ft), although the average altitude of North Afghanistan is about $460 \mathrm{~m}$ $(1509 \mathrm{ft})$ in the Northeastern range it rises to more than $670 \mathrm{~m}(2198 \mathrm{ft})$ and surrounded by China to the 
east, Tajikistan, Uzbekistan to the North, Turkmenist and Herat province in the west, Bamyan, Parwan and Panjsher provinces to the South (Figure 1). Among the 14 laboratories for the COVID-19 test in Afghanistan only two are operating in the North and Northeastern provinces, sometimes stocks of supplies have periodically run out and caused the capacity of these facilities to remain limited. National level capacity for COVID-19 cases testing has topped 5,500 tests per day, but according to World Health Organization (WHO), fewer than 400 tests are being conducted daily due to the shortage of demand means (WHO, 2020). Health services coverage extended, but the quality of services remained poor and only 123 minor and major hospitals with a total of 1355 beds facilities are currently available (NNFS, 2018).

\section{Figure 1: Map of the Study Area in Afghanistan}
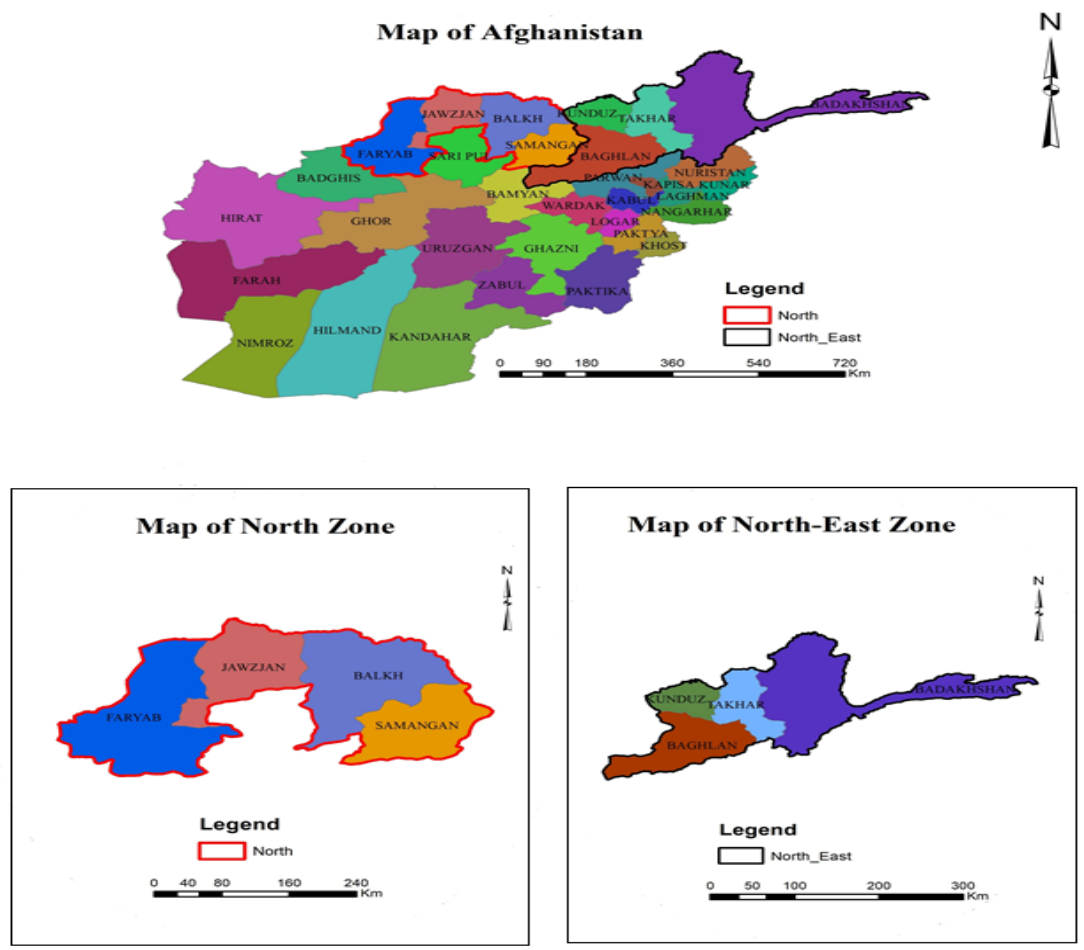

\section{Material and Methods}

The target population was distributed across the 123 minor and major districts of the North and Northeastern regions. Three districts from each province and eighteen households from each district were selected randomly for data collection through the online forms and a telephonic survey (avoiding physical contact as per COVID-19 guidelines). In total 361 individuals out of which 23.05\% (83) were female and around $86.94 \%$ of the respondents were living in the city while $13.06 \%$ of them were living in rural areas at the time of the study. The structured Google form was developed to evaluate diverse dimensions of household-level vulnerability status and their controlling measures. The first part included demographic information, i.e. gender, marital status, education, socio-economic status, occupation, history of family chronic disease, symptoms of COVID-19, and the number of family members visited abroad since January 2020. The second section portrays the exposure levels of respondents to COVID-19. The third section involves the participants' perceptions about the sensitivity, while the fourth account for the information on controlling measures at the household level (Table 1). The questionnaire was prior designed in English and later it was translated into Dari (Official language of Afghanistan) to get user-friendly with the population. 
The Google form link was shared on social networking sites (SNSs), i.e. Facebook and WhatsApp groups with respondents from almost all parts of North and Norther east regions of Afghanistan. The respondents were required to express their agreement before the interviews. The survey did not pursue any information from the respondents that could identify them to ensure the right of privacy of their responses. The framework developed by IPCC was used for the evaluation of the vulnerability index (IPCC, 2007). The vulnerability has a negative functional relationship with a system's adaptive capacity and a positive relationship with a system's exposure and sensitivity (IPCC, 2007). Based on the authors 'consideration from both North and Northeastern regions, along with discussions with peers and published records, various indicators for the study were selected (Bozkurt et al., 2020; Orfan \& Elmyar, 2020; Fitts, et al., 2020). The indicators were normalized on an equal scale based on their functional relationship with vulnerability: for a positive relationship of the indicators with vulnerability equation. (1) was used and equation (2) was used for a negative relationship of the indicators with vulnerability (Omerkhil et al., 2020):

$$
\begin{aligned}
& \text { Index }_{s v}=\frac{S_{v}-S_{\min }}{S_{\max }-S_{\min }} \\
& \text { Index }_{s v}=\frac{S_{\max }-S_{v}}{S_{\max }-S_{\min }}
\end{aligned}
$$

where,

$\mathrm{S}_{\max }$ and $\mathrm{S}_{\min }$ are the maximum and minimum values of the indicator and $\mathrm{S}_{\mathrm{v}}$ is the raw value of the indicator at the interviewer level across the interviewer responses.

After the normalization of each indicator, the components were estimated by averaging all the associated indicators by applying the following formula:

$$
M=\frac{\sum_{i=1}^{n} \text { indecator }}{n}
$$

where $\mathrm{M}$ is the Index value of the components and $\mathrm{n}$ is the number of associated indicators (Omerkhil et al., 2020). After each indicator was normalized, weights for each indicator were estimated for accounting for the relative significance of individual indicators using the method developed by Iyengar and Sudarshan (1982). This weighted method facilitates comparisons among different units and, therefore, ensures that a large variety of the indicator should not unduly dominate the contribution of the rest of the indicators. The weight through this method is evaluated based on numerous stages with the consideration that weights are inversely related with the variation of the relevant indicator of vulnerability as follows:

where,

$$
\begin{gathered}
W_{i}=\frac{K}{\sqrt{\operatorname{var}\left(\text { index }_{\text {svi }}\right)}} \\
K=\left(\sum_{i-1}^{m} \frac{1}{\sqrt{\operatorname{var}\left(\text { Index }_{\text {svi }}\right)}}\right)^{-1}
\end{gathered}
$$

Wi's are weight value of the relative importance of individual component with their momentous properties $0<\mathrm{Wi}<1$ and $\mathrm{W}_{1}+\mathrm{W}_{2}+\ldots .+\mathrm{W}_{\mathrm{m}}=1$ where $\mathrm{m}$ is number of indices.

The vulnerability index (VI) was calculated using the equation described below with value ranges from 0 (minimum) to 1 (maximum), this means the highest value of vulnerability index for a system would be near to the most vulnerable state specifying to highly vulnerable conditions:

$$
V I=E^{*}|S-A|
$$


where,

E, S, and A are the calculated weights of the vulnerability dimensions i.e. Exposure, Sensitivity, and Adaptive Capacity.

Beta distribution was used for the evaluation of different classes of the VI by considering VI as an accidental variable, as per the methodology developed by Iyengar and Sudershan (1982), and by considering three i.e. (0, A1), (A1, A2), (A2, A3) groups, that each class has the equal weight of 33 percent. This classification was used to define the vulnerability status of all provinces surveyed in both regions. The (A1) cut-off points could be acquired from tables of incomplete beta functions with vulnerability categorized as follows:

\begin{tabular}{ll}
\hline Range of value & Vulnerability classes \\
\hline $0<\mathrm{V} 1<\mathrm{A} 1$ & Less vulnerable \\
$\mathrm{A} 1<\mathrm{V} 1<\mathrm{A} 2$ & Vulnerable \\
$\mathrm{A} 2<\mathrm{V} 1<1$ & Very high vulnerable \\
\hline
\end{tabular}

Table 1. Dimensions, components, sub-components, and their functional relationship (F.R) with vulnerability in north and northeast zones of Afghanistan.

\begin{tabular}{|c|c|c|c|}
\hline Dimensions & Components & Sub-components & F.R \\
\hline \multirow{12}{*}{ Exposure } & \multirow{6}{*}{$\begin{array}{l}\text { Impact of } \\
\text { Pandemic } \\
\text { (IP) }\end{array}$} & COVID-19 Patient in Locality & + \\
\hline & & Foreign Tourist Visits from Locality & + \\
\hline & & Vegetable and Fruit Vendor Infected with COVID-19 & + \\
\hline & & Family Member in Frontline Service of COVID-19 & + \\
\hline & & Communities Behavior on Spread of COVID-19 & + \\
\hline & & Panic Created by Media & + \\
\hline & \multirow{3}{*}{$\begin{array}{l}\text { Networking } \\
\text { Decision } \\
\text { (ND) }\end{array}$} & Participation in Social Gathering & + \\
\hline & & Number of Visit Hospital and Grocery Store in Last Two Weeks & + \\
\hline & & Frequency of Meting Friends/Neighbors in One Week & + \\
\hline & \multirow{3}{*}{$\begin{array}{l}\text { Accessibility } \\
\text { (A) }\end{array}$} & Community Support for Prevention of COVID-19 & + \\
\hline & & Hospital in $2 \mathrm{Km}$ Radius & + \\
\hline & & Vegetable Mandi Within 2 Km Radius & + \\
\hline \multirow{11}{*}{ Sensitivity } & \multirow{3}{*}{ Facility $(\mathrm{F})$} & Hygiene Facility & + \\
\hline & & Public Health Surveillance & + \\
\hline & & Availability of Rapid Diagnostic Test Kit and Methods & + \\
\hline & \multirow{2}{*}{$\begin{array}{c}\text { Supportive } \\
\text { Facility (SF) }\end{array}$} & Voluntary to Avoid Large Scale Gatherings & + \\
\hline & & Community Based Activism for Supporting Vulnerable Groups & + \\
\hline & \multirow{6}{*}{ Casualty (C) } & COVID-19 Danger to Elderly Population & + \\
\hline & & COVID-19 Danger to Young Population & + \\
\hline & & Danger of COVID to Impoverished & + \\
\hline & & Danger of COVID to Outdoor Workers & + \\
\hline & & Danger of COVID to People with Chronic Medical Conditions & + \\
\hline & & Compliance Level Towards Citizens & + \\
\hline
\end{tabular}




\begin{tabular}{|c|c|c|c|}
\hline Dimensions & Components & Sub-components & F.R \\
\hline \multirow{24}{*}{$\begin{array}{l}\text { Adaptive } \\
\text { Capacity }\end{array}$} & \multirow{7}{*}{$\begin{array}{l}\text { Protective } \\
\text { Function } \\
\quad(\mathrm{PF})\end{array}$} & Level of Hygiene and Cleanliness & + \\
\hline & & Uses of Mask in Outside & + \\
\hline & & Practicing any Sport to Boost Immune & + \\
\hline & & Intake of Hot Water and Vitamin C Rich Food & + \\
\hline & & Maintaining Physical Distance & + \\
\hline & & Frequency of Hand Wash by Soap in a Day & + \\
\hline & & Frequency of Use Hand Sanitizer in a Day & + \\
\hline & \multirow{2}{*}{$\begin{array}{l}\text { Health } \\
\text { Function } \\
(\mathrm{HF})\end{array}$} & Positively Impact of Lockdown on Mental Health & + \\
\hline & & Negatively Affected of Lockdown on Mental Health & + \\
\hline & \multirow{2}{*}{$\begin{array}{l}\text { Availability } \\
\text { (A) }\end{array}$} & Adequacy of Global Cooperation for the control of COVID-19 & - \\
\hline & & Adequacy of WHO in control of COVID-19 & - \\
\hline & \multirow{3}{*}{$\begin{array}{c}\text { Social } \\
\text { Support (SS) }\end{array}$} & Support Provided by Local Administration & - \\
\hline & & Support from Friends and Neighbors & - \\
\hline & & Food and Dry Ration Support of Most Vulnerable Families & - \\
\hline & \multirow{5}{*}{$\begin{array}{l}\text { Protective } \\
\text { Function } \\
\quad(\mathrm{PF})\end{array}$} & Effectiveness of Ayurveda System of Traditional Medicine & - \\
\hline & & Role of School Education on Hygiene Prevention & - \\
\hline & & Covering Mouth and Nose for Good Respiratory Hygiene & - \\
\hline & & Changing Cloths When Return from Outside & - \\
\hline & & Arrangements of Home Quarantine if Required & - \\
\hline & \multirow{2}{*}{$\begin{array}{c}\text { Livelihood } \\
\text { Support (LS) }\end{array}$} & The Extent of COVID-19 Effect on Normal Activities & - \\
\hline & & The Extent of COVID-19 Influenced Professional Activities & - \\
\hline & \multirow{3}{*}{$\begin{array}{c}\text { Health } \\
\text { Support (HS) }\end{array}$} & The convenience of COVID Prevention Information by Mobile & - \\
\hline & & Frequency of Touching Eyes, Nose, and Mouth in One Hour & - \\
\hline & & Numbers of Persons You Come in Contact $(<1 \mathrm{~m})$ Out of Home & - \\
\hline
\end{tabular}

\section{Data Analysis and Results}

\section{Socio-demographic Status}

This section highlights the results of socio-demographic status for both the North and the Northeast zones of Afghanistan. Across both the regions, living conditions of respondents were poor, they were living in small houses made of local materials, most household $(35.5 \%)$ members were 6 to 50 years old and (31\%) were 50 to 60 and only $11.5 \%$ of respondent family members were more than 60 years of the $91 \%$ were male and $9 \%$ female, however in the Northeast zone $86 \%$ were male and $14 \%$ female (Table 2). Across both regions people were struggling at minimal living standards, education level of the respondent's family witnessed that the proportion of illiterate females was higher than males with very limited access to mobile phones and internet as compared to male respondents. The female members were very nuanced and unfamiliar with the concept of the online and mobile phone survey, therefore female representation is quite low in the present study. Academicians and students $(69 \%$ in the North and $73 \%$ in the Northeast zone) are the chief participants in this study, whereas police personnel made the second-highest percentage (13\% and 5\%) medical professionals third followed by politicians, bankers, and other professionals (Table 3). 
Table 2: Socio-demographic parameters of respondents (in \%).

\begin{tabular}{|c|c|c|}
\hline \multicolumn{3}{|c|}{ Age groups (years) } \\
\hline Parameters & North Zone & North East Zone \\
\hline Below 5 & 23 & 21 \\
\hline $6-50$ & 35 & 36 \\
\hline $50-60$ & 30 & 32 \\
\hline Above 60 & 12 & 11 \\
\hline \multicolumn{3}{|c|}{ Gender } \\
\hline Male & 91 & 86 \\
\hline Female & 9 & 14 \\
\hline \multicolumn{3}{|c|}{ Education } \\
\hline High School & 13 & 0 \\
\hline Intermediate & 27 & 31 \\
\hline Graduation and Above & 60 & 69 \\
\hline \multicolumn{3}{|c|}{ Family Type } \\
\hline Nuclear & 37 & 28 \\
\hline Joint & 63 & 72 \\
\hline
\end{tabular}

Table 3: Occupational status of respondents (in \%).

\begin{tabular}{lcc}
\hline \multicolumn{1}{c}{ Occupation } & North Zone & North East Zone \\
\hline Politician and Bureaucrat & 0 & 4 \\
Academician and Students & 69 & 73 \\
Police & 13 & 5 \\
Business-Grocery Shop & 4 & 5 \\
Medical Professional & 8 & 9 \\
Banking & 3 & 0 \\
Other Services & 3 & 4 \\
\hline
\end{tabular}

Chronic diseases such as diabetes, hypertension, heart diseases, TB/ Sarcoid lung infection were investigated at the household level. These chronic diseases occupy a vivacious role in the mortality and recovering rate of the COVID-19 patients. Whereas diabetes was at a higher percentage in both zones (North 30.4\% and Northeast 29.8\%) subsequently, hypertension (26.1\% and 27.2\%) trailed with cancer $(26.1 \%$ and $25.3 \%$ ) found at a high percentage in both zones respectively. Additionally, $17.4 \%$ of the disease was related to the kidney in the North zone and $15.1 \%$ in the Northeast zone respectively. Lung infections were also reported as a major risk $(13 \%$ in the North and $14 \%$ in the Northeast) by respondents during the survey (Table 4). COVID-19 symptoms such as dry cough, sore throat, diarrhea, fever, runny nose, tiredness, nasal congestion and asthma were found common in all the patients $(78.3 \%$ in the North and $79.4 \%$ in the Northeast). Some cases of fever were also reported (43.5\% in the North and $47.6 \%$ in the Northeast) by the respondent during the survey (Table 4). 
Table 4: Respondent's perception (in \%) on the symptom of COVID-19 and their family chronic diseases history.

\begin{tabular}{lcc}
\hline Chronic Disease History & North Zone & North East Zone \\
\hline Diabetic & 30.4 & 29.8 \\
Hypertension & 26.1 & 27.2 \\
Heart Disease & 13 & 14 \\
Liver Disease & 4.3 & 4 \\
Cancer & 26.1 & 25.3 \\
TB/ Sarcoid & 4.3 & 3.3 \\
Lung Infection & 13 & 14 \\
Kidneys Disease & 17.4 & 15.1 \\
Pulmonary Disease & $\mathbf{0}$ & $\mathbf{2 . 3}$ \\
\hline Symptoms of COVID-19 & & \\
\hline Dry Cough & North Zone & 45.7 \\
Sore Throat & 47.8 & 41.2 \\
Diarrhea & 39.1 & 22 \\
Fever & 26.1 & 47.6 \\
Runny Nose & 43.5 & 35.7 \\
Tiredness & 34.8 & 38.2 \\
Nasal Congestion & 39.1 & 27.2 \\
Asthma & 26.1 & 37.9 \\
All & 39.1 & 79.4 \\
\hline
\end{tabular}

\section{Exposure Assessment}

Key components of the dimensions of exposure were determined based on people's vision and were categorized into three components, the impact of pandemic (defined based on COVID-19 patients, foreign tourists, fruit and vegetable vendors, communities behavior and family member in frontline services of COVID-19 in the locality and panic created by the media), networking decisions (defined based on participation in social gathering and frequency of meeting friends and neighbor in a week) and accessibility (defined based on hospitals and vegetable and fruit markets within $2 \mathrm{~km}$ radius and community support for prevention of COVID-19). In the analysis it was observed that the people of the Northeast zone were more exposed (0.573) to the COVID-19 pandemic, networking decision $(0.081)$ and accessibility (0.312) than people in the Northern region, who were relatively low exposure to the impact of the COVID-19 pandemic (0.434), networking decision (0.387) and accessibility (0.089). The mean value of the exposure index was, 0.910 and 0.966 for North and Northeast regions respectively, it indicates a high exposure of the Northeast region to the COVID-19 pandemic variables in comparison to the North zone people (Table 5. Figure 2). Accessibility was the main concern and was scattered between these two regions varying from hospitals availability, grocery markets and community support in the Northeast zone.

\section{Sensitivity Assessment}

Sensitivity to the COVID-19 pandemic of the North and Northeast zones was constructively based on five components: supportive facility, casualty, protective function and health function spread over eighteen indicators (Table 1). The services were also assessed based on hygiene, public health surveillance and availability of rapid diagnostic test kits. Whereas, supportive facilities involved involuntary actions to avoid gatherings and community-based activities. Additionally, casualties 
have increased the susceptibility level of the elderly and young population, deprived communities, outdoor workers, people with chronic medical conditions and the compliance level towards citizens. The protective function was estimated based on cleanliness practices, frequent uses of masks (in and outside campus), immune-boosting training, regular intake of hot water and vitamin C-rich foods, maintenance of physical distance in and outside the home, regular sanitizing and handwashing. The overall score of the Northeast region for the sensitivity index was 0.664 in comparison to the Northern region provinces of 0.482 . Therefore, the Northeast region was more sensitive to COVID-19 than the Northern zone (Table 5. Figure 2).

\section{Adaptive Capacity Assessment}

The adaptive capacity dimension of vulnerability was considered as a function of socio-economic and capabilities of human beings as well as concerning the accessibility and availability of education, infrastructure and communication facilities (Table 1). All these sub-components were classified under four main components viz., availability of COVID-19 testing kits, health staff, nearby hospitals, social support, protective function and livelihood support. Based on responses the availability index was 0.087 for the North zone and 0.076 for the Northeast zone respectively; social support indexing was 0.083 and 0.064 respectively; protection facility was 0.129 for the North zone and 0.141 for the Northeast zone respectively; livelihood support was 0.176 and 0.154 for North and Northeastern regions respectively. Empirical analysis shows the adaptive capacity index for the both, Northeast and North regions were 0.480 and 0.540 respectively, therefore, people of the Northeast zone have acquired the low-level adaptive capacity to cope with the COVID-19 pandemic risks as compared to the Northern zone. The North zone had higher values of the protective facility (0.129) and higher livelihood support (0.176). Although the Northeast zone had an equal adaptive capacity in terms of the protective facility (0.141) and livelihood support (0.154), the lower levels of availability (0.076) and social support (0.064) made it comparatively less adaptive. Overall, the Northern zone has a higher adaptive capacity (0.540) compared to the Northeast zone (0.480) (Table 5. Figure 2).

\section{Assessment of the vulnerability index}

The present finding shows that communities residing in the Northeast zone were highly vulnerable to the COVID-19 pandemic in terms of vulnerability dimensions i.e., exposure and sensitivity, with very low adaptive capacity to cope with the COVID-19 pandemic risks. Notably, people of the Northern region were also vulnerable, while least exposed, slightly sensitive to the COVID-19 pandemic, possessing a high level of coping capacity than the people of Northeast zone (Table 7). The various triggers, such as poverty and a high dependency on global cooperation, lead the Northeast region to a high vulnerability status. The other justifiable reasons for both zones are the unavailability of hospitals and grocery markets within a radius of two kilometers, lack of primary health and hygiene facilities.

Opportunities for livelihood-generating activities in the Northern zone were quite heightened, whereas, the Northeast zone was facing major job crises which deprived their adaptive capacity (Table 7). Awareness, health and hygiene facilities were reported better in the Northern zone. The individual analysis at the provincial level depicts about $50 \%$ of sampled provinces out of all eight provinces studied in both regions revealed high exposure and the rest $50 \%$ of them showed a modest exposure (Table 6 ). The highest sensitivity was noticed in $25 \%$ of provinces, $50 \%$ were moderately sensitive while $25 \%$ were recorded low sensitivity. The low, moderate and high adaptive capacity to the COVID-19 pandemic risks was observed, respectively. Based on the vulnerability index, $62.5 \%$ of provinces were found highly vulnerable, $25 \%$ moderately and $37.5 \%$ provinces were observed with low vulnerability index. From all eight sampled provinces in both the regions, a high proportion of people were highly exposed, sensitive and vulnerable with devaluated adaptive capacity against the COVID-19 global pandemic. 
Table 5: Status-wise vulnerability dimensions (exposure, sensitivity adaptive capacity) in the north and north east zone.

\begin{tabular}{lllll}
\hline \multirow{2}{*}{ North Zone } & \multicolumn{3}{c}{ Dimensions } \\
\cline { 2 - 5 } & \multicolumn{1}{c}{ Exposure } & Sensitivity & Adaptive Capacity & Vulnerability \\
\hline Faryab & 0.912 & 0.589 & 0.431 & 0.743 \\
Samangan & 0.900 & 0.491 & 0.498 & 0.647 \\
Sheberghan & 0.901 & 0.489 & 0.501 & 0.632 \\
Balkh & 0.897 & 0.324 & 0.657 & 0.589 \\
\hline
\end{tabular}

\begin{tabular}{lllll}
\hline \multirow{2}{*}{ North East Zone } & \multicolumn{3}{c}{ Dimensions } \\
\cline { 2 - 5 } & \multicolumn{1}{c}{ Exposure } & \multicolumn{1}{c}{ Sensitivity } & Adaptive Capacity & Vulnerability \\
\hline Badakhshan & 0.911 & 0.598 & 0.483 & 0.848 \\
Baghlan & 0.810 & 0.432 & 0.434 & 0.825 \\
Takhar & 0.890 & 0.398 & 0.598 & 0.724 \\
Kunduz & 0.901 & 0.486 & 0.515 & 0.706 \\
\hline
\end{tabular}

Almost all the respondents had noticed health variability during the COVID-19 pandemic this year, with more than $86 \%$ of people reporting increasing in COVID-19 cases and health vulnerability from both north and northeast zone provinces of the country. During the survey, individuals expressed their perception towards failing health and hygiene facilities, as most of the people from both zones are deprived and mainly dependent on subsistence health facilities.

Figure. 2. Dimensions of health vulnerability to COVID-19 in both north and northeast zones of Afghanistan.

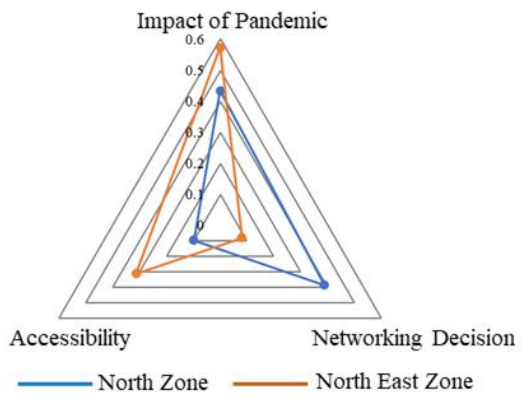

a) Exposure

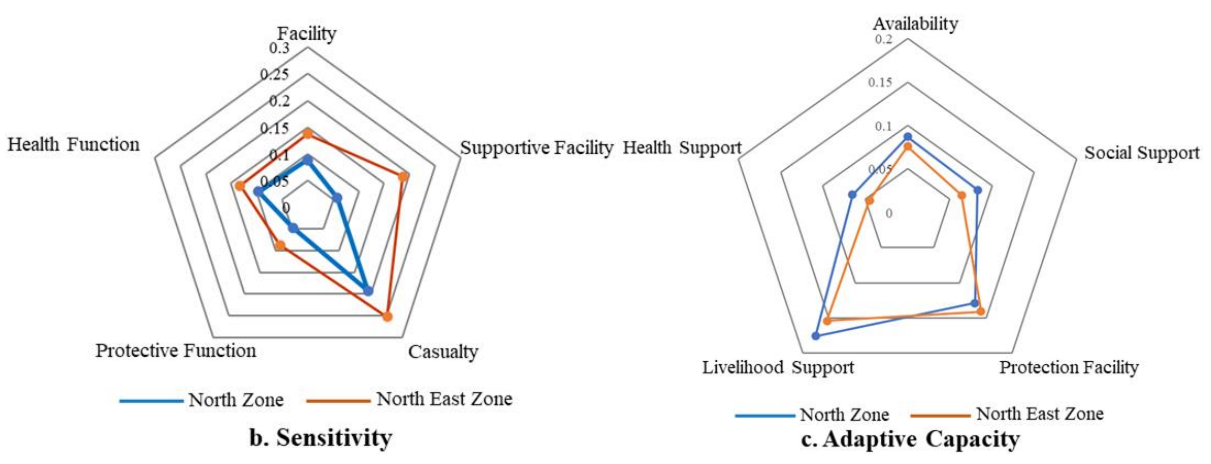


Adaptation or adjustment mechanisms were likely unsettled in both zones due to household food stock shortages and food insecurity, job uncertainty and inaccessibility of governmental and private health care facilities. Moreover, illiteracy and lack of awareness among people supported low adaptability. Although, social support and bartering were new normal in which individual adapting and minimizing the impact of COVID-19 risk. Moreover, people were often subjected to extreme weather events such as conflict and seasonal diseases, resulting in the susceptibility of people to natural hazards and losses of the property.

The present study depicts that health and hygiene insecurity was the major constituent of the coronavirus outbreak. Initiating additional income sources such as Ayurveda (traditional) medicinal supply and suggestions was a big comfort, efforts to improve communities' livelihood dependencies and provide alternatives would minimize vulnerability against COVID-19 or any other pandemic risks in the future (OECD, 2020; Kumar et al., 2021; Simplice et al., 2020).

The majority of the interviewees reported that they noticed health variability during the COVID-19 pandemic this year, with more than $86 \%$ of people reporting an increase in COVID-19 cases and health vulnerability from both the Northern and Northeast zone provinces of the country. The interpretation and understanding of the need to adjust and equip the health and hygiene facilities and their provisions to have effective consequences for their socio-economic livelihood, hygiene, sanitation and health systems. The conditions of poor adaptation mechanisms in both the zones were, maybe, due to the household poverty and food insecurity that caused low household income, unemployment of family members and unavailability of governmental and private healthcare facilities at a radius of two kilometers. All these contributed to restricting people from adopting new pandemic, health and hygiene facilities that were available in their respective regions (Bozkurt et al., 2020; Orfan \& Elmyar, 2020; Fitts, et al., 2020; Singh, 2020). Illiteracy and poor awareness were other reasons for low adaptability among people; social support and bartering were the only way people adapted to the impact of COVID-19 pandemic risks; people were frequently exposed to extreme weather events, conflict and seasonal diseases, resulting in susceptibility of people to natural hazards such as the COVID-19 pandemic and loss of property like the destruction of agriculture land, home and losses of their family members. The results of this study are quite in harmony with the assessments of significant livelihood impact on health and hygiene facilities reported in earlier studies (Saikia, et al., 2020; Wyper et al., 2020; Orfan et al., 2020; James et al., 2020).

The generation of additional income source or using the Ayurveda system of traditional medicine, covering the face with masks and keeping a physical distance when going outside, washing hands regularly with hand sanitizer and soap, preventing mouth, nose and eyes from touching and changing clothes after coming from outside, working from home and online are the alternative options that they described as a way of coping with medical and medicinal scarcities. These adaptive measures assist people to moderate the effect of the pandemic, however, they are insufficient to cope with serious medicinal and health care shortages and insecurity ( Cabril et al., 2021; WHO, 2020; Asongu et al., 2020; Kuhn \& Nennstiel, 2020). Healthcare, hygiene, medicinal shortages and the supplementary adaption approaches for an auxiliary medicinal production were predominantly addressed by using the Ayurveda system of traditional medicines elsewhere, and all these measures were insufficient due to the limited availability of medicinal herbs and shrubs and also time-specific nature of medicinal plants (UNDP, 2020; Basu, 2020; Sahana, et al., 2020). Furthermore, few available medical centers lacked basic services because of poor infrastructure and it caused tremendous difficulties to healthcare workers to promote healthcare and hygiene services and activities. Thus, people were bound to be constantly dependent on these poor medical services as reported (WHO, 2020; Prisno et al., 2020; Sahana et al., 2020; Imdad, et al., 2020). An effort to improve the healthcare, hygiene and livelihood of people would desire to focus on increasing the facilities of healthcare and hygiene system as soon as possible and saving people from the COVID -19 pandemic vulnerability to COVID-19 or other similar 
pandemic hazards in the future through diverse types of interventions (OECD, 2020; Kumar et al., 2021; Acharya \& Porwal., 2020). Other options that may effectively increase healthcare and hygiene facilities in the study regions include facilitating access to quality health services, medicines, hospitals, clinics and other inputs, improving the infrastructure of hospitals and medical clinics and access to quality medical services and stipulating specialized expertise and medical services to the people. Our investigation shows the medical services for the provision of technical aspects and training on the best management practices for disease pandemic outbreak would boost the acceptance of new ways to raise public awareness and reduce vulnerability (Macharia, et al., 2020; UN, 2020; Singh, 2020; Mukherjee et al., 2020). A small-scale infrastructure setup, such as vaccination, availability of the hospital and medical clinic, would further help these people's health and hygiene and safeguard their health. Access to credit, accessibility to the function facilities and welfare nets during catastrophic events, like the COVID-19 pandemic or other common disease epidemics, would prepare people with the capability to address the risks and encourage them to attain better hygiene and health facilities. Suitable programmes and policies with alternative livelihood support and healthcare system intensification are required to improve disadvantage distracts and communities' welfare and reduce their vulnerability, Special attention is required. Socio- economic and environmental may be additional choice for adaptation mechanism for people as illustrated by (Macharia, et al., 2020; Asongu et al., 2020; Shah et al., 2020; Mishra et al., 2020). Furthermore, infrastructure such as education, socio-environmental and more facilities along with rural development programmes with governmental and non-governmental sponsorships have to be properly developed to improve overall welfare and further assist people to responding the negative effect of any pandemic outbreak (World Bank, 2020; OCHA, 2021; Adams, et al., 2020;Mosavie et a., 2020;Saeed, 2020; Macharia, et al., 2020a).

Table 6: Dimensions, components, and index value for the vulnerability estimation of north and northeast.

\begin{tabular}{llllll}
\hline \multirow{2}{*}{ Dimensions } & \multicolumn{1}{c}{ Components } & \multicolumn{2}{c}{ Weight of Components and Dimensions } \\
\cline { 3 - 5 } Exposure & Impact of Pandemic (IP) & 0.434 & & North Zone & \multicolumn{2}{c}{ North East Zone } \\
\hline & Networking Decision (ND) & 0.387 & 0.434 & 0.081 & 0.966 \\
& Accessibility (A) & 0.098 & & 0.312 & \\
\hline \multirow{5}{*}{ Sensitivity } & Facility (F) & 0.089 & & 0.137 & \\
& Supportive Facility (SF) & 0.058 & & 0.187 & \\
& Casualty (C) & 0.192 & 0.482 & 0.253 & 0.664 \\
& Protective Function (PF) & 0.047 & & 0.087 & \\
& Health Function (HF) & 0.096 & & 0.132 & \\
\hline \multirow{5}{*}{ Adaptive Capacity } & Availability (A) & 0.087 & & 0.076 & \\
& Social Support (SS) & 0.083 & & 0.064 & \\
& Protection facility (PF) & 0.129 & 0.540 & 0.141 & 0.480 \\
& Livelihood Support (LS) & 0.176 & & 0.154 & \\
& Health Support (HS) & 0.065 & & 0.045 & \\
\hline
\end{tabular}

\section{Conclusions}

The current COVID-19 pandemic has spread across the globe, unleashing health crises and economic shocks on trades, foreign direct investments, supply chains and suspended globalization and causing a vast range of vulnerability on various systems across the world. The impact of the COVID-19 
pandemic on health and human socioeconomic systems is high and depends on the scale of the outbreak, communities development, and sensitivity besides the varieties and implementation of adaptation and mitigation measures (Omerkhil et al., 2020; Zhag et al., 2017). Underdeveloped countries have been hit the hardest, particularly Afghanistan for its poor health and hygiene infrastructure and strategies, due to the absence of financial, institutional and technical, support. This study intends to assess the health vulnerability profile and identify the control mechanism of the Northern and Northeast regions of Afghanistan using the IPCC framework. The province's health vulnerability status was classified into different groups, based on the vulnerability index, $62.5 \%$ of provinces were highly vulnerable, $25 \%$ moderately and $37.5 \%$ least vulnerable. In the Northeast region, people were highly vulnerable to COVID-19 in terms of sensitivity and exposure, with a low coping capacity to cope with COVID-19 risks compared to the Northern zone. The finding of our study revealed a high frequency of diseases outbreak, inaccessible clinical necessities, insufficient COVID-19 assessment kits, lack of health experts, and infrastructure setups are the main reasons for a high risk of vulnerability in both regions. The improved health and hygiene facilities enhancing awareness and understanding of these households, implementing preventative measures and a handful of low-cost methods such as strengthening informal safety nets and introducing small-scale regional infrastructure projects, could be the most cost-effective and viable options to decrease the ill impacts of COVID-19. The forthcoming coping mechanism should comprise learnings about disaster basic materialistic support, pandemic responses and mitigation strategies, and for overall household welfare. However, still empirical evaluation is required to understand the influence of COVID-19 on the entire nation, combining a relationship between indicators and their influence on local communities. The results of this research may provide a base to modify the current strategies and framework in the many underdeveloped and developing countries of the globe, where people are under the threats of the COVID-19 risk.

\section{Declarations}

-Ethical Assent: While preparing this manuscript, strictly all the ethical principles have been followed.

-Consent to Participants: NA

-Consent to Publish: NA

\section{Author contribution statement}

NK, NO, and GS conceptualized, designed, and developed online Google form and analyzed the data; AA, NO, and GA collected the data and NO modified the primary version, and NK read and revised the final revision, $\mathrm{NO}$ and GS were the overall coordinators of the paper.

\section{Sources of funding}

This research was not sponsored by any governmental, commercial, public, or not-for-profit funding agencies and sectors.

\section{Statement of Competing Interest}

The authors declare no potential conflict of interest.

\section{Acknowledgments}

NO, NK, GS, AA, GA are grateful and wish to thank the Kunduz university, faculties, and students for providing their timely support and facilities to carry out the online and mobile survey in this research. We also thank all the participants for sharing their responses and providing support. 


\section{References}

Acharya, r., and Powal, A. (2020). A vulnerability index for the management of and respons to the COVID-19 epedemic in India: an eclological study. Vol I (9).The Lancet Glob Health. https//doi.org/10.1016/ S2214.10gx(20)30300-4

Adams, S. H., Park, M. J., Schaub, J. P., Brindis, C. D., and Irwin, C. E. (2020). Medical vulnerability of young adults to severe COVID-19 illnessdata from the national health interview survey. Journal of Adolescent Health, 67(3), 362-368.

ANDS, (2018). Afghanistan national development strategy (2018-af): A strategy for Security, governance, economic growth and poverty reduction. Gul Khana Palace, (Sedarat) Kabul, Afghanistan

Asongu, S., Diop, S., and Nnanna, J. (2020). Health vulnerability versus economic resilience to the COVID-19 pandemic: Global Evidence. Working paper of European Xtramile Center of African Studies (EXCAS). SSRN Electronic Journal. https://doi.org/10.2139/ssrn.3714288

Basu, S. (2020). Estimating vulnerability to COVID-19 in India correspondence estimating vulnerability. The Lancet Global Health 8(12), e1465.

Bhattacharya, M. and Banerjee, P. (2021). COVID-19: indices of economic and health vulnerability for the Indian states. Journal of Science and Humanities.

Bozkurt, F., Yousef, A. and Abdel jawad, T. (2020). Analysis of the outbreak of the novel coronavirus COVID-19 dynamic model with control mechanisms. Results in Physics.

Cabril, IE., Pestana-Santos, M., Ciuff, LL., Nunes, YR. and Lomba, MLLF. Child health vulnerabilities during the COVID-19 pandemic in Brazil and Portugal. Ravista Latino-Americana de Enfermagem. 2021;29e3422. Available in www.eerp.usp.br/rlae.

FAO. (2020). International conference on nutrition - 20 years later ( ICN + 20 ) FAO / WHO. https://www. researchgate.net/publication/3445604634

Fitts, M. S., Russell, D. J., Mathew, S., Liddle, Z., Grad, E. and Wakerman, J. (2020). Remote health service vulnerabilities and responses to the COVID-19 pandemic. Australian Journal of Rural Health. 2020;00:15. https://doi.org/10.1111/ ajr.12672

Husseini, A. A., and Kamil A. A. (2020). Estimating COVID-19 dynamics in afghanistan. Erciyes Medicalournal. 42(0): 00-00. . https//doi.org/ 10.14744/etd.2020.80270

Imdad, K., Sahana, M., Rana, J. M., Haque, I., Patel, P.P. and Pramanik, M. (2020). A district-level susceptibility and vulnerability assessment of the COVID-19 pandemic's footprint in India. patial Spatial and SpatioTemporal Epidemiology. vol (36)., 100390.

IPCC, (2007) .Climate Change 2007: Impacts, adaptation and vulnerability, in: Parry, M.L., Canziani, O.F., Palutikof, J.P., van der Linden, P.J., Hanson, C.E. (Eds.), Contribution of Working Group II to the Fourth Assessment Report of the Intergovernmental Panel on Climate Change, Cambridge University Press, Cambridge, UK, 976p

Iyenger, N.S., and Sudarshan, P., (1982). A method of classifying regions from multivariate data. Economic and Political Weekly, 17 (51): 2047-2052. https://www.jstor.org/stable/4371674

Jaiswal, A., and Kooko, R. (2021). COVID-19: evaluation of occupational health risk and healthcare workers. Anthropology and Ethnology Open Access Journal. Vol 4(1).

James, k., Gibb, L., Zachary, DuBois., Sara, Williams., Luseadra, Mc. Robert, Paul juster., and Jessica, fields. (2020). Sexual and gender minority health vulnerability during the COVID-19 health crisis. American Journal of Human Biology.

Kumar, P., Singh, S. S., Pandey, A. K., Kumar, R., Kumar, P., Kumar, M., and Drews, M. (2021). Multi-level impacts of the COVID-19 lockdown on agricultural systems in India: The case of Uttar Pradesh. agricultural systems. 187, 103027. https://doi.org/10.1016/j.agsy.2020.103027

kuha, J,. Muhle, U., and Nennstiel, U., (2020). Protecting vulnerable populations from COVID-19 why health governance and operations matter to implement interventions fast. Bavarian perspective. The Journal of 
Health Management. and Organistion. (20),9.

Mishra, S. V., Gayen, A., and Haque, S. M. (2020). COVID-19 and urban vulnerability in India. US National Library of Medicine, National Institue of Health. Habitat International. 103, 102230. https//doi.org/1016/j. habitatint.2020.102230

MoPH. (Afghanistan Ministry of Public Health) (2020). Measures and actions taken by the Ministry of Public health to prevent and control the spread of the new coronavirus in Afghanistan. Kabul; https://moph.gov. af/dr/

Mousavi, Sayed Hamid., Shafi Ullah, Zahid., Kalimullah, Wardak., Kazim Ali, Azimi., Alfonso, J., and Rodriguez, Morales. (2020). Mapping the changes on incidence, case fatality rates and recovery proportion of COVID-19 in Afghanistan using geographical information systems. 1-3. https://doi.org/10.1016/j. arcmed.2020.06.010

Macharia, P. M., Joseph, N. K., and Okiro, E. A. (2020a). vulnerability index for COVID-19: spatial analysis at the subnational level in Kenya. BMJ Global Health 2020;5:e003014.

MANAGE. (2015). Demand analysis report: Islamic Republic of Afghanistan. National Institute of Agricultural Extension Management, Hyderabad, India

Miller, Matthew Repine. (2017). Understanding the vulnerability status of Afghanpopulationunder multiple natural and anthropogenic risks with an indicator-based analysis. Master's Thesis, University of Tennessee,. https:// trace.tennessee.edu/utk_gradthes/4764

Mukherjee, S., Dasgupta, P., Chakroborty, M., and Biswas, G. (2020). Vulnerability of major India states due to COVID-19 spread and lockdown. Institue of Development Studies Kolkata. Available online at www.idsk. edu.in https//bit.ly/2O0y20

NRVA. (2018). National risk and vulnerability assessment 2018/2019: a profile of Afghanistan. Kabul, Afghanistan. https://www.af.undp.org

NNFS, National Nutrition and Food Security (NNFS) (2018). National Nutrition and Food Security Country Paper Afghanistan International (NNFS) A profile of Afghanistan. Jehoon Printing Press, Kabul, Afghanistan. https://www.fao.org

OECD. (2020). COVID-19 : Protecting people and societies tackling coronavirus (COVID-19) contributing to global effort.: http://www.oecd.org/termsandconditions

Omerkhil, N., Chand, T., Valente, D., Alatalo, J. M., and Pandey, R. (2020). Climate change vulnerability and adaptation strategies for smallholder farmers in Yangi Qala District, Takhar, Afghanistan. Ecological Indicators, 110 (June 2019), 105863.

Orfan, S. N., and Elmyar, A. H. (2020). Public knowledge, practices and attitudes towards COVID-19 in Afghanistan. Public Health of Indonesia, 6(4), 104-115.

OCHA. (2021). Strategic situation report: COVID-19. Afghanistan humanitarian response plan (2018- 2021) mid-year monitoring report 84(84). www.unocha.org

Prisno, Don., Eliseo, Lucero., Attaullah, Ahmadi., Mohammad Yasir, Essar., Xu, Lin. and Yusuff, Adebayo. (2020). Addressing COVID-19 in Afghanistan : What are the efforts and challenges ?. www.jogh.org. Vol. 10 No. 2. 020341. https://doi.org/10.7189/jogh.10.020341

Saikia, Prastuti., Arun Jyoti, Nath., Rakesh, Kumar., Pramod K. Singh., and Rajiv, Pandey. (2020). Vulnerability to climate change among the Inhabitants of Majuli Island. ISSN 2454-7115 Working Paper 314.: https:// www.researchgate.net/publication/346997555

Saeed, I. M. K,. (2020). Epidemiological characteristics of coronavirus disease 2019 (COVID-19). Global Academic Journal of Medical Science 2(4) 31-40. ISSN: 2706-9028 (O); https//doi.org/10.36346.GAJMS. v02i04.003 Avi;http/:gajrc. gajrc.com/gajms

Sahana, M., Haque, I., Patel, P. and Rana, J. M,. (2020). The COVID-19 pandemic's footprint in India: An assessment on the district-level susceptibility and vulnerability. doi.org/10.13140/RG.2.2.18295.24483. 
https://mpra.ub.uni-muenchen.de/100727.

Shah, J., Karimzadeh, S., Al-ahdal, T. M. A., Mousavi, S. H., Zahid, S. U., and Huy, N. T. (2020). COVID-19 : the current situation in Afghanistan. The Lancet Global Health, (April), 20-22.

Surendra, S. (2020). Bridging the gap between social and health vulnerability in rural India : A case of Covid-19. Vol. 13 (10). https://doi.org/10.1016/j.dib.2020.106020

Safi, N,. and Ibrahimi, S.S. (2020). Coping with COVID-19 and Conflict in Afghanistan. Center on International Cooporation. Kabul, Afghanistan https://cic.nyu.edu

Simplice, A., Asongu, Samba Diop., and Joseph, Nnanna. (2020). Health vulnerability versus economic and resilience to the COVID-19 pandemic: Global evidence. Working paper of European Xtramile center of African studies (EXCAS). SSRN Electronic Journal. https// doi.org/10.2139/ssm.3714288

Surendra, Singh. (2020). Data on social and health vulnerability in rural India: A case of COVID-19. https//doi. org/10.1016/j.did.2020.106020

United Nations Office for the Coordination of Humanitarian Affairs (UNOCHA) (2020). Afghanistan flash update: Daily Brief: COVID-19, No. 40 (30 April 2020) - Afghanistan (https://reliefweb.int/report/afghanistan/ afghanistan-flash-update-daily-brief-covid-19-no-40-30- april-2020)

UN Habitat. (2019). COVID-19 Vulnerability in informal settlements: A case study of an urban IDP Community in Jalalabad, Afghanistan. united nations human settlements programme (UN Habitat) Afghanistan. UNOCA Complex, Jalalabad Road Kabul Afghnsistan. www.unhabitat.af

UNDP (United Nation Developed Programme) (2020). Covid-19 and social protection of poor and vulnerable groups in Latin America : A conceptual framework. UNDP Latin America and the Caribbean, (8). UNDP Latin America and the Caribbean. www.latinamerica.undp.org

Viola, M., Najimi, F.K., Bacon, B., (2007). Afghanistan food security conditions and causes: a special report by the Famine Early Warning Systems Network (FEWS NET). United States Agency for International Development Famine Early Warning Systems Network, Washington, DC

WFP. (2019). Afghanistan annual country report 2018: Country strategic plan 2018-2022. https://docs. wfp.org/api/documents/WFP,0000104251/download/?_ga=2.121653771.168334 360.1555209166585466690.1555209166

WHO. (2020a). Timeline of WHO's response to COVID-19. Retrieved from https://www.who.int/news-room/ detail/29-06-2020-covidtimeline

WHO. (2020). Protecting the vulnerable Current global situation . Journal of the American Dental Association, 141(7), 827. https://doi.org/10.14219/jada.archive.2010.0268

World Bank. (2011). World Bank open data. The World Bank; FAO, accessed in May 2019. https://data.worldbank. org/country/afghanistan

World Bank. (2014a). Islamic Republic of Afghanistan agricultural sector review revitalizing agriculture for economic growth. Job Creation Food Security. 297. https://data.worldbank.org/country/afghanistan

World Bank. (2020b). Turn down the heat confronting the new climate normal, regional summaries. international bank for reconstruction and development/the. World Bank 1818 H Street NW, Washington DC, 20433. https://www.researchgate.net/publication/345813082

Wyper, M. A., Assuncao, R, Cuschieri, S., Devleesschauwer, B., Fletcher, E., Haagsma, J., Henk, B., M, Idavain, J., and Rrant, Ian. (2020). Population vulnerability to COVID-19 in Europe: A burden of disease analysis. Archives of Public Health. https/ doi.org/10.1186/s13690-020-00433-y

Yihun, Kalkidan, Lakew. (2020). Rapid gender analysis COVID-19 in Afghanistan. http://gender.care2share. wikispaces.net/Gender+in+Emergencies

Zhang, H., Wu, J., Gao, Y., Chen, Z., (2017). Spatial assessment of ecological vulnerability in Fuzhou district in China using remote sensing and GIS. Nature Environment and Pollution Technology an International Quaterly Scientific Journal, 16 (4). eISSN: 2395-3454 